Article

\title{
Synthesis of a New Ruthenate $\mathrm{Ba}_{26} \mathrm{Ru}_{12} \mathrm{O}_{57}$
}

\author{
Jeong-Eun Lee, Ulrich Burkhardt and Alexander Christoph Komarek* \\ Max-Planck-Institute for Chemical Physics of Solids, Nöthnitzer Str. 40, D-01187 Dresden, Germany; \\ JeongEun.Lee@cpfs.mpg.de (J.-E.L.); Burkhardt@cpfs.mpg.de (U.B.) \\ * Correspondence: alexander.komarek@cpfs.mpg.de
}

Received: 24 March 2020; Accepted: 27 April 2020; Published: 30 April 2020

\begin{abstract}
Single crystals of $\mathrm{Ba}_{26} \mathrm{Ru}_{12} \mathrm{O}_{57}$ were grown by the floating zone method. The crystal structure is formed by an alternating stacking of pseudo-hexagonal $\mathrm{Ru}$ single layers and double layers. The $\mathrm{Ru}$ ions within the double layers are dimerized $\left(\mathrm{Ru}_{2} \mathrm{O}_{9}\right)$ whereas the $\mathrm{Ru}$ ions within the single layers arrange in a distorted Kagome lattice of trigonal bipyramidally coordinated $\mathrm{RuO}_{5}$ polyhedra. Additionally, this Kagome lattice is "decorated" with $\mathrm{RuO}_{6}$ octahedra that are situated in the central free spaces within this Kagome lattice. According to the composition, the oxidation state of most of the $\mathrm{Ru}$ ions should be formally close to $5+$.
\end{abstract}

Keywords: Ruthenate; singe cyrstal growth; floating zone technique; dimer; Kagome; high oxidation state

\section{Introduction}

Ruthenates exhibit a broad scope of interesting physical properties ranging from itinerant ferromagnetism in $\mathrm{SrRuO}_{3}$ [1] and metamagnetim in $\mathrm{Sr}_{3} \mathrm{Ru}_{2} \mathrm{O}_{7}$ [2,3] to unconventional superconductivity in $\mathrm{Sr}_{2} \mathrm{RuO}_{4}$ [4] (see also the reviews [5,6]). Recently, it was tried to dope Ba ions into $\mathrm{Sr}_{2} \mathrm{RuO}_{4}$ [7-9]. For the compound $\mathrm{Sr}_{1.6} \mathrm{Ba}_{0.4} \mathrm{RuO}_{4}$ the Ba-doping was still possible but for distinctly higher Ba-doping levels no single crystals could be grown anymore by the floating zone technique. It seems possible that a miscibility gap might appear above these Ba-doping levels within the $\mathrm{Sr}_{2-x} \mathrm{Ba}_{x} \mathrm{RuO}_{4}$ phase diagram (for ambient pressure, high temperature synthesis conditions). Therefore, we investigated the other side of the phase diagram around $\mathrm{Ba}_{2} \mathrm{RuO}_{4+\delta}$.

Within the ternary Ba-Ru-O system, $\mathrm{Ba}_{1} \mathrm{Ru}_{1} \mathrm{O}_{3}$ is known to exist and crystalizes in different polytypes depending on the synthesis pressure (9R, $4 \mathrm{H}, 6 \mathrm{H}$ and possibly 3C) [10]. The crystal structure at ambient pressure (nine-layer rhombohedral 9R) $\mathrm{Ba}_{1} \mathrm{Ru}_{1} \mathrm{O}_{3}$ consists of $\mathrm{Ru}$ trimers with $\mathrm{Ru}^{4+}$ ions sitting in face sharing Ru-oxygen octahedra [11]. For increasing $\mathrm{Ba}$ to $\mathrm{Ru}$ ratio also the compounds with the $\mathrm{Ba}$ to $\mathrm{Ru}$ ratio 4:3, 5:3 and 5:2 are known to exist. For $\mathrm{Ba}_{4} \mathrm{Ru}_{3} \mathrm{O}_{10}$ corner-shared $\mathrm{Ru}_{3} \mathrm{O}_{12}$ trimers are formed [12] and the material is antiferromagnetic with a magnetic ordering temperature of $\mathrm{T}_{N} \sim 105 \mathrm{~K}$ [13]. For $\mathrm{Ba}_{5} \mathrm{Ru}_{3} \mathrm{O}_{12} \mathrm{Ru}$ trimers are formed [14] whereas the compound $\mathrm{Ba}_{5} \mathrm{Ru}_{2} \mathrm{O}_{10}$ is crystallizing in a structure formed of Ru-Ru dimers [15]. However, for these two compounds the dimers are not interconnected with other dimers (or trimers) like in the aforementioned Ba ruthenates with lower $\mathrm{Ba}$ to $\mathrm{Ru}$ ratio. Instead, the planes with the $\mathrm{Ru}-\mathrm{Ru}$ dimers are separated by $\mathrm{Ba}$ oxide planes. For such high levels of the $\mathrm{Ba}$ to $\mathrm{Ru}$ ratio the $\mathrm{Ru}$ ions (also) appear formally in a higher 5+ oxidation state. For the $\mathrm{Ba}$ to $\mathrm{Ru}$ ratio of 2:1 (which would be the end point in the $\mathrm{Sr}_{2-x} \mathrm{Ba}_{x} \mathrm{RuO}_{4}$ phase diagram) no compound in single crystalline form has been reported to exist so far. However, for this $\mathrm{Ba}$ to $\mathrm{Ru}$ ratio studies on thin films [16] or high pressure phases [17]—both with layered perovskite structure-exist.

\section{Results and Discussion}

The $\mathrm{Ba}_{26} \mathrm{Ru}_{12} \mathrm{O}_{57}$ single crystal was grown in a mirror furnace (HKZ,Scidre). Therefore, the starting materials were prepared by thorough grinding of $\mathrm{BaCO}_{3}$ and $\mathrm{RuO}_{2}$ with a $\mathrm{Ba}$ to $\mathrm{Ru}$ ratio of 2:1 and 
sintering this mixture at $1000{ }^{\circ} \mathrm{C}$ for one day in air. The crystal was grown with a speed of $6 \mathrm{~mm} / \mathrm{h}$ under 16 bar of an Argon/Oxygen atmosphere (with a ratio of 1:6). Thus, black, shiny single crystals of $\mathrm{Ba}_{26} \mathrm{Ru}_{12} \mathrm{O}_{57}$ could be finally obtained, see Figure 1 . As known for other ruthenates, also during the growth of $\mathrm{Ba}_{26} \mathrm{Ru}_{12} \mathrm{O}_{57}$ a larger evaporation of $\mathrm{Ru}$ oxide could be observed during the crystal growth which explains the finally obtained Ba:Ru ratio in the grown single crystal. Also other Ba:Ru ratios of 2:1.1 and 2:1.05 have been tried for a compensation of the Ru loss, but only the ratio of 2:1 results in the growth of large impurity-free single crystals of $\mathrm{Ba}_{26} \mathrm{Ru}_{12} \mathrm{O}_{57}$. Its composition has been confirmed with EDX (energy dispersive $\mathrm{X}$-ray spectroscopy) measurements in a scanning electron microscope yielding a molar Ba:Ru ratio of 2.07(8):1.00(5) which is within the error bars in agreement with the composition of $\mathrm{Ba}_{26} \mathrm{Ru}_{12} \mathrm{O}_{57}$.

Afterwards, we have also synthesized $\mathrm{Ba}_{26} \mathrm{Ru}_{12} \mathrm{O}_{57}$ powder samples by conventional solid state reaction in order to confirm that our $\mathrm{Ba}_{26} \mathrm{Ru}_{12} \mathrm{O}_{57}$ single crystals crystallized in the ambient pressure phase. Therefore, stoichiometric amounts of $\mathrm{BaCO}_{3}$ and $\mathrm{RuO}_{2}$ (molar ratio of 26:12) were ground for $1 / 2 \mathrm{~h}$ and pressed into pellets which were placed in a corundum crucible and sintered at $1000{ }^{\circ} \mathrm{C}$ for $12 \mathrm{~h}$ in air. After an intermediate re-grinding the sample was sintered again for $48 \mathrm{~h}$ under same conditions at ambient pressure.

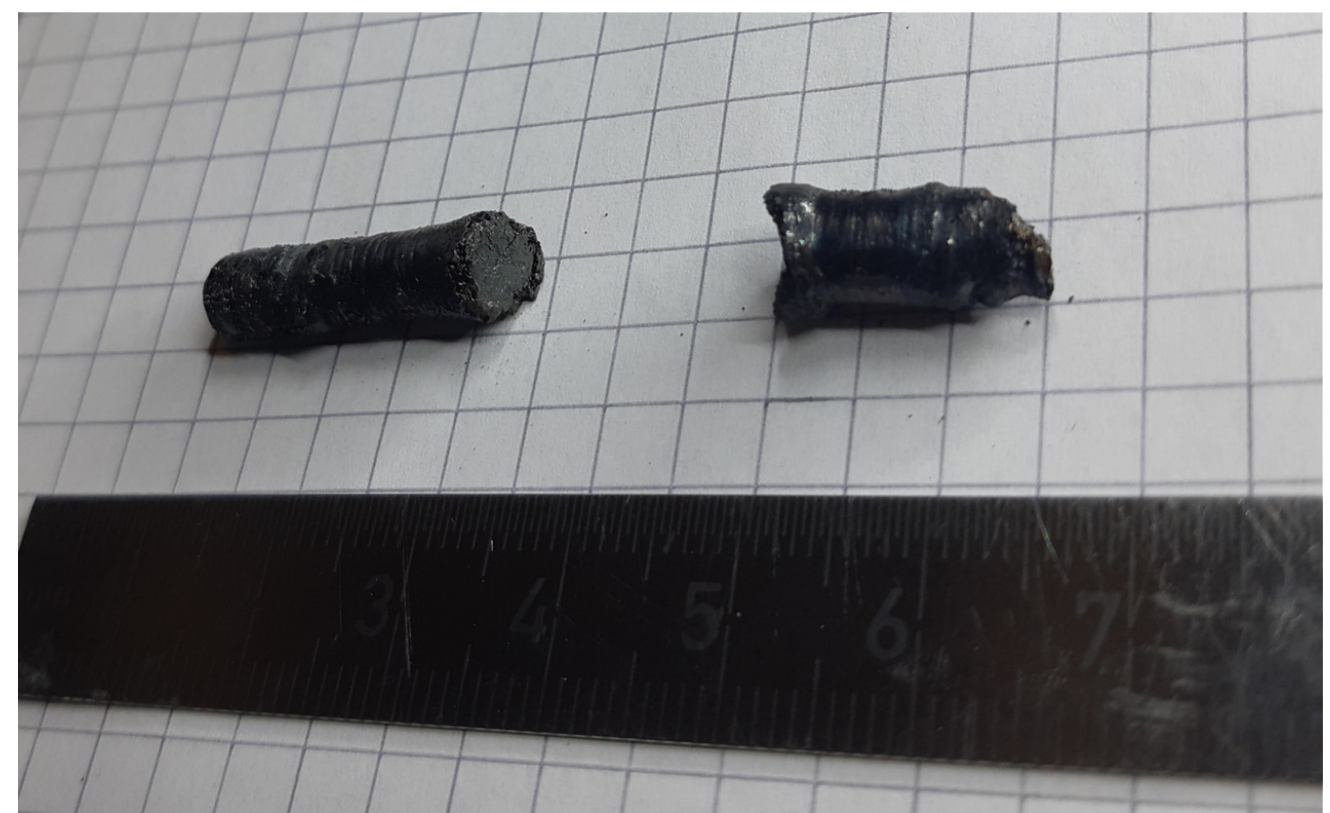

Figure 1. Photo of the as-grown $\mathrm{Ba}_{26} \mathrm{Ru}_{12} \mathrm{O}_{57}$ single crystal in the left (with a ruler below that is showing large ticks in units of $1 \mathrm{~cm}$ ).

For powder X-ray diffraction (XRD) measurements parts of the grown single crystals have been ground into fine powders. The XRD measurements have been performed using $\mathrm{Cu} K_{\alpha 1}$ radiation on a Bruker D8 Discover A25 powder X-ray diffractometer. The FullProf program package [18] was used for Rietveld refinements, see Figure 2. 


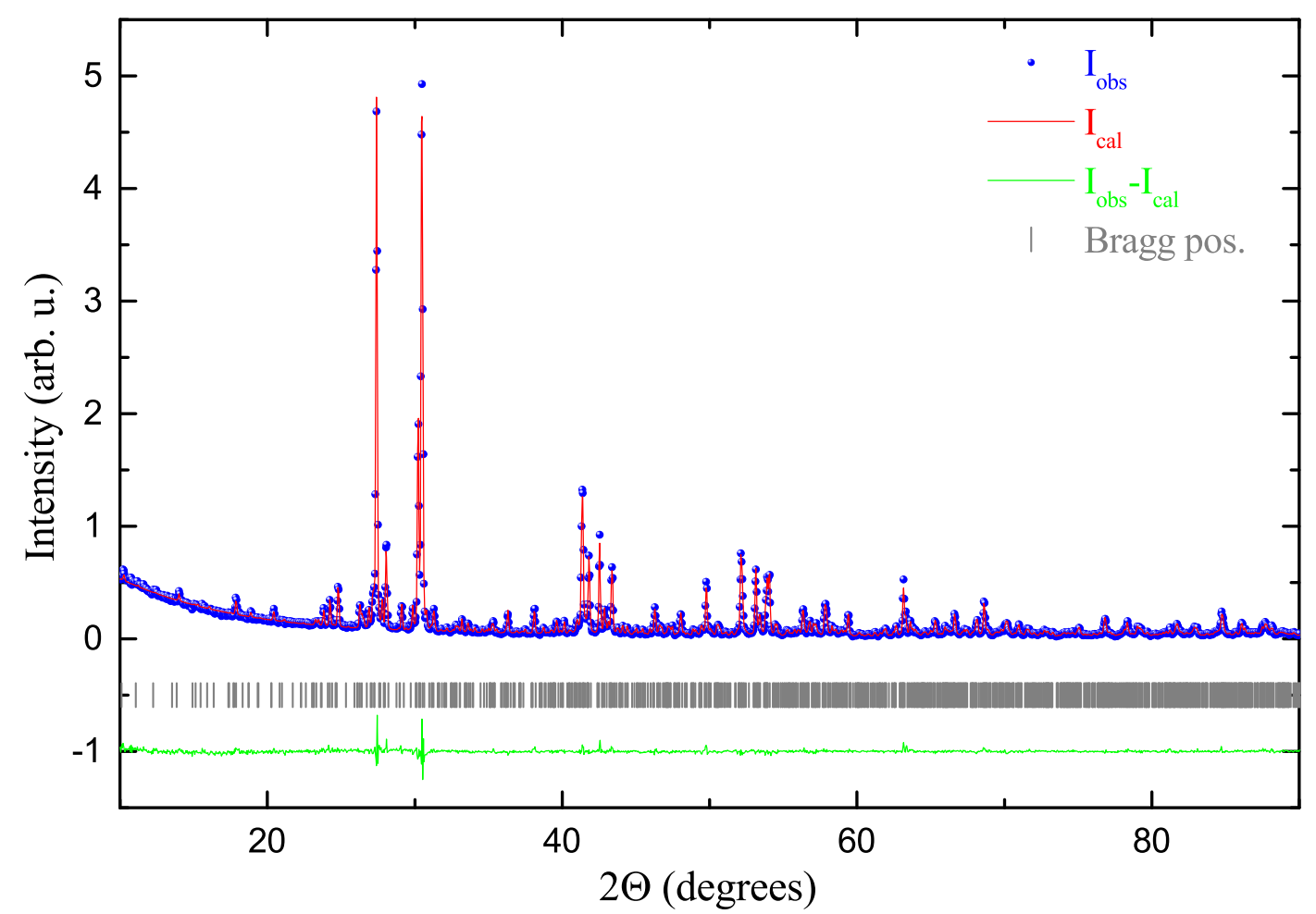

Figure 2. Powder $\mathrm{X}$-ray diffraction pattern $\left(\mathrm{Cu}-\mathrm{K}_{\alpha_{1}}\right)$ of the grown $\mathrm{Ba}_{26} \mathrm{Ru}_{12} \mathrm{O}_{57}$ single crystal collected at room temperature. The red solid line represents a Rietveld fit based on the structure model obtained by single crystal X-ray diffraction (using the FullProf software package [18]). The calculated Bragg peak positions (according to space group Fdd2) are indicated by vertical bars and the difference between the experimental and calculated intensities are shown by the green solid line at the bottom. The obtained lattice parameters (space group Fdd2) amount to $a=20.4536(4) \AA, b=51.1908(8) \AA$ and $c=11.7732(2) \AA$.

Using Mo $K_{\alpha}$ radiation single crystal X-ray diffraction measurements have been performed on a Bruker D8 VENTURE single crystal X-ray diffractometer equipped with a bent graphite monochromator and a Photon III detector. A crystal of roughly $10 \mu \mathrm{m}$ size has been measured, see Figure 3. Due to the small size of the sample we were able to find an almost untwined single crystal with regard to the possible orthorhombic twin domains. Nevertheless, the inversion twin could not be avoided. (For distinctly larger sample sizes we could always observe the appearance of all six possible twin domains that might appear for this structure.) The Jana2006 program suite [19] was used for the crystal structure refinement. The refinement was based on $F(\mathrm{obs})^{2}$ with an instability factor of 0.01 . For this tiny sample no extinction correction was necessary. The volume fractions of the main domain (id) and the corresponding twin domain obtained by inversion (-id) amount to $49(3) \%$ and $40(1) \%$ whereas the remaining four twin domains related to rotations (plus inversions) are very small (i.e., $1.6(1.6) \%, 2.4(1.6) \%, 2.5(1.6) \%$ and $4.1 \%$ ) with a volume fraction almost comparable to their error bars. The reduced amount (size) of twin domains in this sample with pseudo-hexagonal crystal structure underlines the reliability of the refinement results. Only for the heavier atoms $\mathrm{Ba}$ and $\mathrm{Ru}$ the anisotropic displacement parameters $U_{i, j}$ have been refined. For the oxygen atoms $U_{i s o}$ has been refined. Goodness of fit, R- and weighted R-values and the obtained structural parameters and bond lengths are listed in Tables $1-4$. 
OKL

HOL

HKO

Figure 3. Single crystal X-ray diffraction intensities of $\mathrm{Ba}_{26} \mathrm{Ru}_{12} \mathrm{O}_{57}$ within the $0 K L, H 0 L$ and $H K 0$ planes of reciprocal space (space group $14 / \mathrm{mmm}$ ). 
Table 1. Crystallographic \& structural refinement data.

\begin{tabular}{|c|c|}
\hline Empirical formula & $\mathrm{Ba}_{26} \mathrm{Ru}_{12} \mathrm{O}_{57}$ \\
\hline Formula weight (g/mol) & 5696.1 \\
\hline Temperature & room temperature \\
\hline Wavelength & $\mathrm{Mo} \mathrm{K}_{\alpha}$ \\
\hline Crystal system & orthorhombic \\
\hline Space group & $F d d 2(43)$ \\
\hline Unit cell dimensions & $\begin{array}{l}a=20.4638(12) \AA \\
b=51.191(3) \AA \\
c=11.7698(7) \AA\end{array}$ \\
\hline Volume & $12,329.5(13) \AA^{3}$ \\
\hline Z & 8 \\
\hline Density $\left(\mathrm{g} / \mathrm{cm}^{3}\right)$ & 6.1372 \\
\hline Absorption coefficient $\mu$ & 19.234 \\
\hline$F(000)$ & 19,520 \\
\hline Crystal size & $\sim 10 \mu \mathrm{m}$ \\
\hline $2 \Theta_{\max }$ & $64.12^{\circ}$ \\
\hline Index range & $\begin{array}{l}h:-30 \rightarrow 30 \\
k:-76 \rightarrow 76 \\
l:-17 \rightarrow 17\end{array}$ \\
\hline Reflections in total/independant & $340,765 / 21,135$ \\
\hline Observed reflections/independant & $256,056 / 19,031$ \\
\hline Internal R-value & $4.54 \%$ \\
\hline Completeness up to $2 \Theta_{\max }$ & $99.89 \%$ \\
\hline Absorption correction & multi-scan \\
\hline Max./min. transmission & $0.5463 / 0.7463$ \\
\hline Refinement method & least squares on $F^{2}$ \\
\hline Reflections threshold & $I>3 \sigma(I)$ \\
\hline Goodness of fit & 2.19 \\
\hline $\mathrm{R} / \mathrm{R}_{w}$ & $3.07 \% / 7.80 \%$ \\
\hline Largest minima in Fourier difference & $-1.20 \mathrm{e}^{-} \AA^{-3}$ \\
\hline Largest maxima in Fourier difference & $1.94 \mathrm{e}^{-} \AA^{-3}$ \\
\hline
\end{tabular}

Table 2. Refinement results of single crystal X-ray diffraction measurements of $\mathrm{Ba}_{26} \mathrm{Ru}_{12} \mathrm{O}_{57}$ of the refinement with space group Fdd2 ( $a=20.4638(12) \AA, b=51.191(3) \AA, c=11.7698(7) \AA)$.

\begin{tabular}{lcccc}
\hline Atom & $\mathbf{x}$ & $\mathbf{y}$ & $\mathbf{z}$ & $\mathbf{U}_{\text {iso }}\left(\AA^{2}\right)$ \\
\hline Ba1 & $0.65079(2)$ & $0.208323(7)$ & 0.1563 & $0.01467(10)$ \\
Ba2 & $0.999319(17)$ & $0.085696(6)$ & $0.20177(7)$ & $0.00981(8)$ \\
Ba3 & $0.170861(19)$ & $0.041104(7)$ & $0.20207(6)$ & $0.01739(10)$ \\
Ba4 & $0.82290(2)$ & $0.219793(7)$ & $0.24056(5)$ & $0.01327(10)$ \\
Ba5 & $0.354973(17)$ & $0.032130(7)$ & $0.21110(6)$ & $0.01728(9)$ \\
Ba6 & $0.32153(2)$ & $0.216648(7)$ & $0.17447(5)$ & $0.01444(11)$ \\
Ba7 & $0.167785(18)$ & $0.124818(6)$ & $0.20302(8)$ & $0.01096(8)$ \\
Ba8 & $0.70055(2)$ & $0.041117(7)$ & $0.21087(6)$ & $0.02095(11)$ \\
Ba9 & $0.89407(3)$ & $0.040235(9)$ & $0.00885(5)$ & $0.02325(13)$ \\
Ba10 & $0.500566(18)$ & $0.080283(7)$ & $0.20496(7)$ & $0.01392(9)$ \\
Ba11 & $0.000746(16)$ & $0.164118(6)$ & $0.20603(7)$ & $0.00952(8)$ \\
Ba12 & $0.501251(17)$ & $0.162389(6)$ & $0.20568(7)$ & $0.00925(8)$ \\
Ba13 & $0.666246(17)$ & $0.124834(6)$ & $0.20821(8)$ & $0.01113(8)$ \\
Ru1 & $0.83331(2)$ & $0.103263(7)$ & $0.20564(8)$ & $0.00665(10)$ \\
Ru2 & $0.33370(2)$ & $0.151882(7)$ & $0.20507(8)$ & $0.00661(10)$ \\
Ru3 & $0.33503(2)$ & $0.097675(7)$ & $0.20691(8)$ & $0.00672(10)$ \\
Ru4 & $0.83275(2)$ & $0.156070(8)$ & $0.20657(8)$ & $0.00678(10)$ \\
Ru5 & 0.5 & 0 & $0.21206(10)$ & $0.00769(15)$ \\
Ru6 & $0.50515(3)$ & $0.249290(8)$ & $0.21046(10)$ & $0.01119(11)$ \\
\hline
\end{tabular}


Table 2. Cont.

\begin{tabular}{|c|c|c|c|c|}
\hline Atom & $x$ & $\mathbf{y}$ & $\mathbf{z}$ & $\mathrm{U}_{\text {iso }}\left(\AA^{2}\right)$ \\
\hline Ru7 & 0 & 0 & $0.19733(10)$ & $0.01396(19)$ \\
\hline O1 & $0.1229(2)$ & $0.57513(9)$ & $0.0740(4)$ & $0.0096(9)$ \\
\hline $\mathrm{O} 2$ & $0.2552(2)$ & $0.58445(8)$ & $0.2062(5)$ & $0.0141(8)$ \\
\hline $\mathrm{O} 3$ & $0.1258(3)$ & $0.32816(11)$ & $0.0876(5)$ & $0.0163(11)$ \\
\hline $\mathrm{O} 4$ & $0.25532(19)$ & $0.17114(8)$ & $0.2035(5)$ & $0.0108(7)$ \\
\hline O5 & $0.2429(2)$ & $0.42234(8)$ & $0.2063(5)$ & $0.0147(8)$ \\
\hline O6 & $0.1296(3)$ & $0.82271(11)$ & $0.0898(5)$ & $0.0194(12)$ \\
\hline O7 & $0.2545(2)$ & $0.67576(8)$ & $0.2060(5)$ & $0.0153(8)$ \\
\hline O8 & $0.2028(3)$ & $0.37512(8)$ & $0.0939(4)$ & $0.0090(10)$ \\
\hline O9 & $0.1223(3)$ & $0.07778(10)$ & $0.0714(4)$ & $0.0102(9)$ \\
\hline O10 & $0.1262(3)$ & $0.42173(10)$ & $0.0887(4)$ & $0.0155(10)$ \\
\hline O11 & $0.1281(3)$ & $0.91493(9)$ & $0.0864(4)$ & $0.0119(9)$ \\
\hline $\mathrm{O} 12$ & $0.2042(2)$ & $0.87099(9)$ & $0.0928(4)$ & $0.0074(9)$ \\
\hline O13 & $0.09182(19)$ & $0.87039(7)$ & $0.2025(5)$ & $0.0098(7)$ \\
\hline O14 & $0.09121(19)$ & $0.37525(7)$ & $0.2059(5)$ & $0.0091(7)$ \\
\hline $\mathrm{O} 15$ & $0.1229(2)$ & $0.17197(10)$ & $0.0751(4)$ & $0.0107(9)$ \\
\hline O16 & $0.1229(3)$ & $0.66528(9)$ & $0.0729(4)$ & $0.0142(10)$ \\
\hline $\mathrm{O} 17$ & $0.0472(3)$ & $0.12503(9)$ & $0.0677(4)$ & $0.0112(10)$ \\
\hline O18 & $0.0421(2)$ & $0.47838(10)$ & $0.0913(4)$ & $0.0166(9)$ \\
\hline O19 & $0.0279(3)$ & $0.96359(10)$ & $0.1966(6)$ & $0.0312(12)$ \\
\hline $\mathrm{O} 20$ & $0.0786(2)$ & $0.52270(8)$ & $0.2076(5)$ & $0.0168(8)$ \\
\hline $\mathrm{O} 21$ & $0.0150(4)$ & $0.71228(13)$ & $0.1873(7)$ & $0.0492(19)$ \\
\hline $\mathrm{O} 22$ & $0.0078(3)$ & $0.21343(12)$ & $0.2369(6)$ & $0.0392(16)$ \\
\hline $\mathrm{O} 23$ & $0.0756(3)$ & $0.00744(11)$ & $0.1199(5)$ & $0.0265(12)$ \\
\hline $\mathrm{O} 24$ & $0.0452(3)$ & $0.62015(10)$ & $0.0702(4)$ & $0.0106(9)$ \\
\hline $\mathrm{O} 25$ & 0.25 & 0.75 & $0.0983(6)$ & $0.0206(14)$ \\
\hline $\mathrm{O} 26$ & $0.0736(3)$ & $0.25183(10)$ & $0.1366(5)$ & $0.0223(11)$ \\
\hline $\mathrm{O} 27$ & $0.0785(3)$ & $0.75492(12)$ & $0.1292(5)$ & $0.0287(12)$ \\
\hline $\mathrm{O} 28$ & $0.2101(3)$ & $0.22822(10)$ & $0.0825(4)$ & $0.0173(10)$ \\
\hline $\mathrm{O} 29$ & $0.2418(4)$ & $0.49459(14)$ & $0.1135(6)$ & $0.0428(16)$ \\
\hline
\end{tabular}

Table 3. Refinement results of single crystal X-ray diffraction measurements of $\mathrm{Ba}_{26} \mathrm{Ru}_{12} \mathrm{O}_{57}$.

\begin{tabular}{|c|c|c|c|}
\hline Atom & $\mathrm{U}_{11}\left(\AA^{2}\right)$ & $\mathrm{U}_{22}\left(\AA^{2}\right)$ & $\mathrm{U}_{33}\left(\AA^{2}\right)$ \\
\hline Ba1 & $0.01598(19)$ & $0.01027(16)$ & $0.01775(19)$ \\
\hline $\mathrm{Ba} 2$ & $0.01068(15)$ & $0.00795(12)$ & $0.01081(16)$ \\
\hline Ba3 & $0.01431(16)$ & $0.01217(14)$ & $0.02569(19)$ \\
\hline Ba4 & $0.01802(19)$ & $0.00930(15)$ & $0.01250(17)$ \\
\hline Ba5 & $0.01249(15)$ & $0.01051(14)$ & $0.02885(19)$ \\
\hline $\mathrm{Ba} 6$ & $0.0205(2)$ & $0.00795(15)$ & $0.0148(2)$ \\
\hline Ba7 & $0.00906(14)$ & $0.01393(13)$ & $0.00988(16)$ \\
\hline Ba8 & $0.02028(18)$ & $0.01712(17)$ & $0.0254(2)$ \\
\hline Ba9 & $0.0248(2)$ & $0.0231(2)$ & $0.0218(2)$ \\
\hline Ba10 & $0.01128(16)$ & $0.01918(15)$ & $0.01129(16)$ \\
\hline Ba11 & $0.00932(14)$ & $0.00804(12)$ & $0.01119(15)$ \\
\hline Ba12 & $0.00949(14)$ & $0.00785(12)$ & $0.01041(15)$ \\
\hline Ba13 & $0.00979(15)$ & $0.01347(13)$ & $0.01013(16)$ \\
\hline Ru1 & $0.00610(17)$ & $0.00638(16)$ & $0.00747(17)$ \\
\hline $\mathrm{Ru} 2$ & $0.00665(18)$ & $0.00582(16)$ & $0.00736(18)$ \\
\hline Ru3 & $0.00650(17)$ & $0.00651(16)$ & $0.00716(17)$ \\
\hline $\mathrm{Ru} 4$ & $0.00673(18)$ & $0.00627(15)$ & $0.00733(18)$ \\
\hline Ru5 & $0.0082(3)$ & $0.0076(2)$ & $0.0073(3)$ \\
\hline Ru6 & $0.01110(19)$ & $0.00691(16)$ & $0.0156(2)$ \\
\hline Ru7 & $0.0232(3)$ & $0.0082(2)$ & $0.0105(4)$ \\
\hline
\end{tabular}


Table 3. Cont.

\begin{tabular}{|c|c|c|c|}
\hline Atom & $\mathrm{U}_{12}\left(\AA^{2}\right)$ & $\mathrm{U}_{13}\left(\AA^{2}\right)$ & $\mathrm{U}_{23}\left(\AA^{2}\right)$ \\
\hline Ba1 & $-0.00120(14)$ & $-0.00363(15)$ & $-0.00249(13)$ \\
\hline $\mathrm{Ba} 2$ & $-0.00129(11)$ & $-0.00031(16)$ & $0.00017(15)$ \\
\hline Ba3 & $-0.00332(13)$ & $0.00150(19)$ & $-0.00277(16)$ \\
\hline $\mathrm{Ba} 4$ & $0.00047(13)$ & $0.00177(13)$ & $0.00054(12)$ \\
\hline $\mathrm{Ba} 5$ & $0.00103(12)$ & $0.00066(19)$ & $0.00177(16)$ \\
\hline Ba6 & $0.00056(13)$ & $-0.00395(14)$ & $-0.00033(12)$ \\
\hline Ba7 & $0.00103(12)$ & $-0.0013(2)$ & $-0.00129(15)$ \\
\hline Ba8 & $-0.00772(14)$ & $0.0032(2)$ & $0.00001(18)$ \\
\hline Ba9 & $0.01344(18)$ & $-0.00860(18)$ & $-0.01232(16)$ \\
\hline Ba10 & $-0.00026(13)$ & $0.00042(17)$ & $0.0016(2)$ \\
\hline Ba11 & $-0.00102(11)$ & $0.00087(18)$ & $-0.00106(16)$ \\
\hline Ba12 & $-0.00057(11)$ & $0.00028(18)$ & $0.00026(17)$ \\
\hline Ba13 & $0.00243(11)$ & $-0.0001(2)$ & $0.00155(15)$ \\
\hline $\mathrm{Ru} 1$ & $0.00016(14)$ & $-0.00077(19)$ & $-0.0001(2)$ \\
\hline $\mathrm{Ru} 2$ & $-0.00025(14)$ & $0.0000(2)$ & $0.0002(2)$ \\
\hline $\mathrm{Ru} 3$ & $-0.00054(14)$ & $-0.00053(19)$ & $-0.0008(2)$ \\
\hline $\mathrm{Ru} 4$ & $0.00022(14)$ & $0.0000(2)$ & $-0.0001(2)$ \\
\hline Ru5 & $0.0001(2)$ & 0 & 0 \\
\hline Ru6 & $-0.00109(14)$ & $-0.0059(2)$ & $0.00244(17)$ \\
\hline $\mathrm{Ru} 7$ & $-0.0059(3)$ & 0 & 0 \\
\hline
\end{tabular}

Table 4. Ru-oxygen distances in $\mathrm{Ba}_{26} \mathrm{Ru}_{12} \mathrm{O}_{57}$.

\begin{tabular}{lll}
\hline Atoms & Distance & Coordination \\
\hline Ru1-O2 & $1.867(4)$ & octahedral \\
Ru1-O11 & $1.861(5)$ & \\
Ru1-O12 & $2.022(5)$ & \\
Ru1-O13 & $2.042(4)$ & \\
Ru1-O16 & $1.861(5)$ & \\
Ru1-O24 & $2.068(5)$ & \\
\hline Ru2-O3 & $1.909(6)$ & octahedral \\
Ru2-O4 & $1.883(4)$ & \\
Ru2-O8 & $2.044(5)$ & \\
Ru2-O9 & $1.893(5)$ & \\
Ru2-O14 & $2.071(4)$ & \\
Ru2-O17 & $2.053(5)$ & \\
\hline Ru3-O5 & $1.895(4)$ & octahedral \\
Ru3-O8 & $2.075(5)$ & \\
Ru3-O10 & $1.884(5)$ & \\
Ru3-O14 & $2.049(4)$ & \\
Ru3-O15 & $1.884(5)$ & \\
Ru3-O17 & $2.062(5)$ & \\
\hline Ru4-O1 & $1.874(5)$ & octahedral \\
Ru4-O6 & $1.914(6)$ & \\
Ru4-O7 & $1.892(4)$ & \\
Ru4-O12 & $2.069(5)$ & \\
Ru4-O13 & $2.054(4)$ & \\
Ru4-O24 & $2.044(5)$ & \\
\hline Ru5-O18 & $1.997(5)$ & octahedral \\
Ru5-O18 & $1.997(5)$ & \\
Ru5-O20 & $1.986(4)$ & \\
Ru5-O20 & $1.986(4)$ & \\
Ru5-O28 & $1.980(5)$ & \\
Ru5-O28 & $1.980(5)$ & \\
\hline & & \\
& \\
\hline
\end{tabular}


Table 4. Cont.

\begin{tabular}{lll}
\hline Atoms & Distance & Coordination \\
\hline Ru6-O21 & $1.924(7)$ & trigonal bipyr. \\
Ru6-O22 & $1.952(6)$ & \\
Ru6-O26 & $1.832(5)$ & \\
Ru6-O27 & $1.803(6)$ & \\
Ru6-O29 & $1.818(7)$ & \\
\hline Ru7-O19 & $1.949(5)$ & trigonal bipyr. \\
Ru7-O19 & $1.949(5)$ & \\
Ru7-O23 & $1.835(6)$ & \\
Ru7-O23 & $1.835(6)$ & \\
Ru7-O25 & $1.777(7)$ & \\
\hline
\end{tabular}

\section{Structure}

The crystal structure of $\mathrm{Ba}_{26} \mathrm{Ru}_{12} \mathrm{O}_{57}$ alternatingly consists of layers of single $\mathrm{Ru}$ ions and of layers of dimerized Ru-ions located in face sharing octahedra which are denoted in Figure 4 as layers 'A\#' (Ru single layers) and 'B\#' (Ru double layers) respectively. Within these Ru-layers the Ru ions arrange in a pseudohexagonal manner, see Figure 5. Two third of the Ru ions within the 'A\#' layers have a trigonal bipyramidal oxygen coordination—-see Figure 5a-with an enhanced oxidation state compared to the other Ru ions, see Table 5. These Ru ions form a distorted Kagome lattice. The other $\mathrm{Ru}$ ions are octahedrally coordinated by the oxygen ions, see Figure 5a and are situated in the free space of the Kagome lattice. This difference in the Ru sites becomes also apparent in their Ba coordination which can be seen in Figure $5 b$. The $\mathrm{RuO}_{6}$ octahedra are located in quite compact $\mathrm{RuBa}_{6}$ octahedra (red) wheras the $\mathrm{RuO}_{5}$ bipyramids are situated in much larger $\mathrm{RuBa}_{12}$ icosahedra (yellow). The dimerized $\mathrm{Ru}$ ions within the ' $\mathrm{B \#}$ ' layers all form $\mathrm{Ru}_{2} \mathrm{O}_{9}$ polyhedra consisting of two face sharing $\mathrm{RuO}_{6}$ octahedra. The corresponding Ru-Ba polyhedra (orange) exhibit more uniform sizes compared to the ones within the 'A\#' (single-)layers, see Figure 5d. It is the different stacking ('A1-B1-A2-B2-A3-B1'-A4-B2'-A1') of these layers that is responsible for the large value of the lattice constant in $b$-direction, compare Figure 4. Note, that also the heavy Ba-ions follow this stacking.

For many Ba-containing compounds the Ba ions are twelve-fold coordinated by anions as is observed for $\mathrm{Ba} 7, \mathrm{Ba} 10$ and $\mathrm{Ba} 13$ in $\mathrm{Ba}_{26} \mathrm{Ru}_{12} \mathrm{O}_{57}$. An example in literature is $\mathrm{BaNiO}_{3}$ [20]. But also a plethora of other oxygen coordinations have been reported for $\mathrm{Ba}$ in literature. The $\mathrm{Ba} 1$ ions in our new crystal structure exhibit an 8-fold oxygen coordination that can be also found e.g., in $\mathrm{Ba}_{3} \mathrm{OSiO}_{4}$ [21]. A different 8-fold oxygen coordination in our new crystal structure can be observed for the $\mathrm{Ba} 4, \mathrm{Ba} 5$ and Ba6 ions. This latter oxygen coordination was reported for $\mathrm{Ba}_{3}\left(\mathrm{BO}_{3}\right)_{2}$ [22]. Also an octahedral anionic coordination is known for $\mathrm{Ba}$ (although an octahedral oxygen coordination is much more typical for somewhat smaller but still very large $\mathrm{Sr}^{2+}$ ions) and has been reported for $\mathrm{Ba}_{2} \mathrm{CuO}_{2} \mathrm{Cl}$ [23]. The oxygen coordination of the Ba ions is also summarized in Table 5. The Ba-O polyhedra are characterized by three values given in brackets. The central values denotes the amount of oxygen ions that are situated very roughly in the plane of the Ba-ion (perpendicular to the pseudohexagonal axis). The first and the last values denote the number of oxygen ions far above and below this plane. [e.g., an octahedral coordination would be abbreviated by (3-0-3).] A cif-file is provided as a Supplementary Materials File for a detailed visualization. 


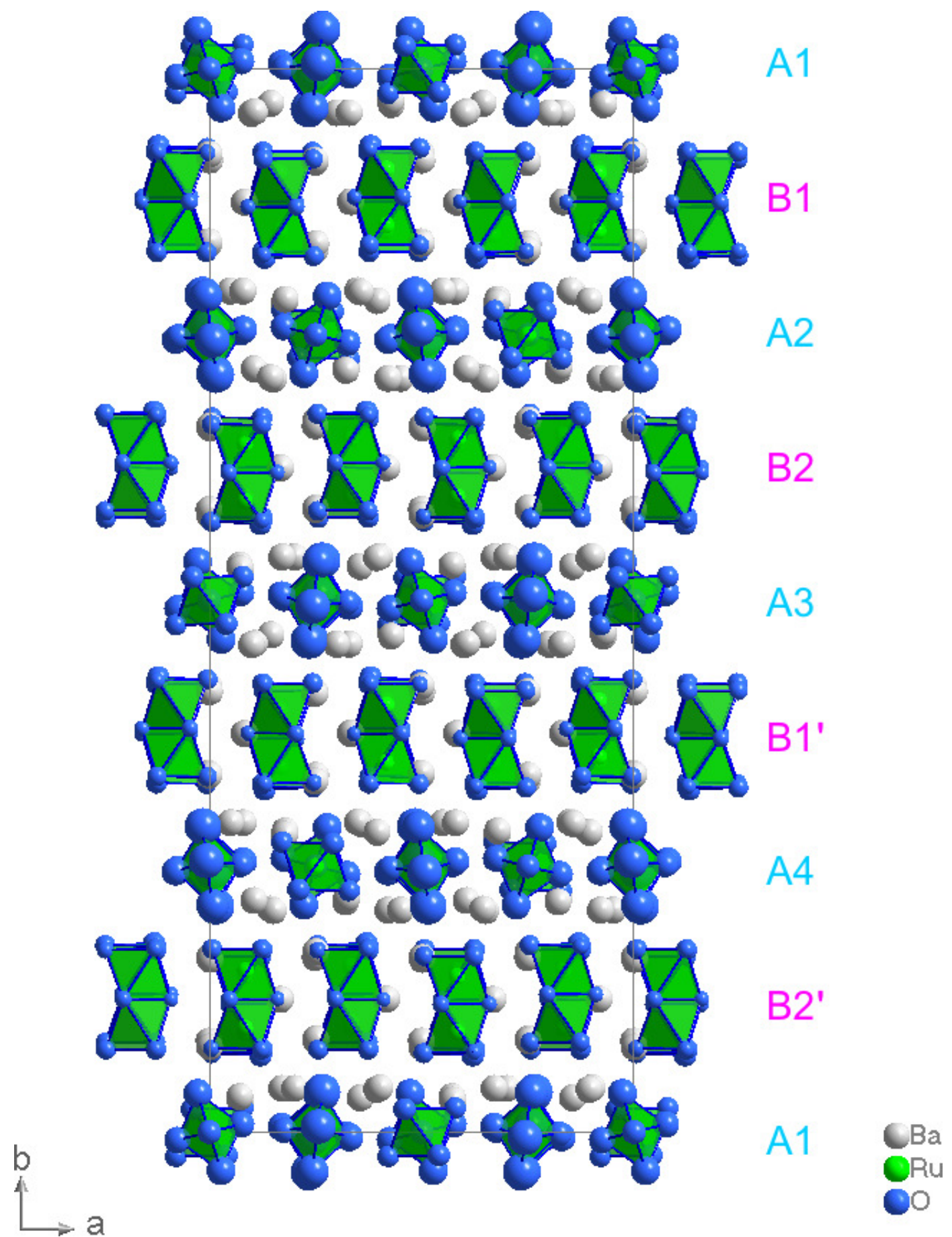

Figure 4. Representation of the crystal structure of $\mathrm{Ba}_{26} \mathrm{Ru}_{12} \mathrm{O}_{57}$ as obtained from refinements with space group Fdd2. Green/white spheres: Ru-/Ba-ions, blue spheres: 99.9\% probability ellipsoids for the oxygen ions. 
(a)

(c)

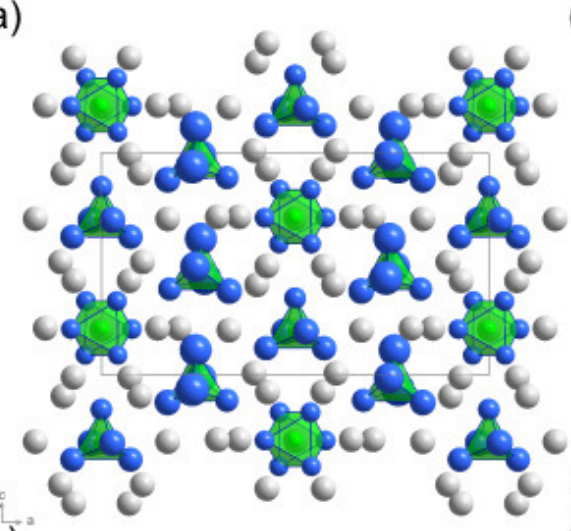

(b)

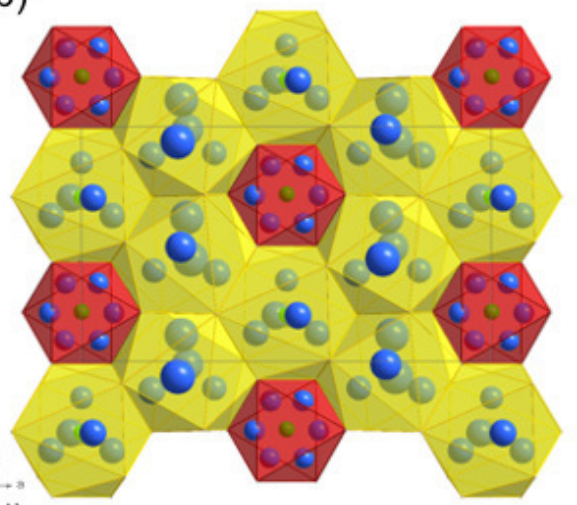

(d)

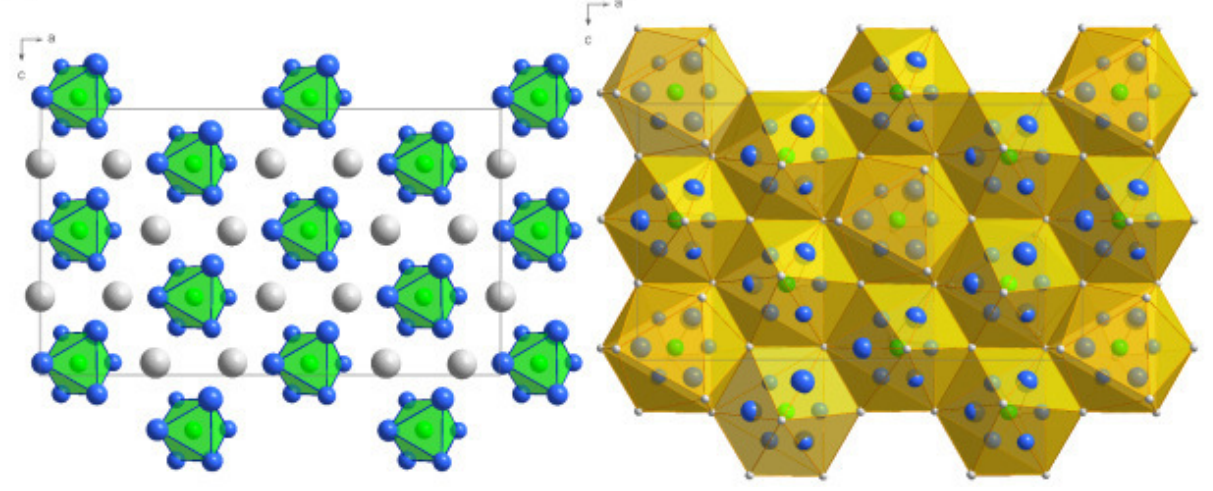

Figure 5. (a,b) represent the Ru oxygen layer 'A3' shown in Figure 4. Accordingly, (c,d) represent the $\mathrm{Ru}$ oxygen doublelayer of type 'B2'. Green/white spheres: Ru-/Ba-ions, blue spheres: 99.9\% probability ellipsoids for the oxygen ions. In $(\mathbf{a}, \mathbf{c})$ the $\mathrm{RuO}_{5}$ and $\mathrm{RuO}_{6}$ polyhedra are shown wheras the Ru-Ba-polyhedra are shown in $(\mathbf{b}, \mathbf{d})$.

Table 5. Bond valence sums (BVS) for Ba and Ru ions together with their oxygen coordination. Parameters were taken from Ref. [24]. The values in the brackets indicate the number of the of oxygen ions that are (i) distinctly below, (ii) roughly within and (iii) clearly above the plane of the Ru ions (that is perpendicular to the $b$-axis) for a certain layer.

\begin{tabular}{llrl}
\hline Atom & BVS & av. O-Distance & O-Coordination \\
\hline Ba1 & $2.25(1)$ & $2.79(16)$ & 8-fold (2-5-1) \\
Ba2 & $2.25(1)$ & $2.88(17)$ & 10-fold (3-6-1) \\
Ba3 & $2.23(1)$ & $2.67(12)$ & octahedral (3-0-3) \\
Ba4 & $2.41(1)$ & $2.76(14)$ & 8-fold (3-4-1) \\
Ba5 & $2.25(1)$ & $2.80(20)$ & 8-fold (3-4-1) \\
Ba6 & $2.40(1)$ & $2.77(19)$ & 8-fold (3-4-1) \\
Ba7 & $1.95(1)$ & $2.98(11)$ & 12-fold (3-6-3) \\
Ba8 & $2.17(1)$ & $2.81(16)$ & 8-fold (3-3-2) \\
Ba9 & $2.16(1)$ & $2.82(18)$ & 8-fold (3-3-2) \\
Ba10 & $1.77(1)$ & $3.05(22)$ & 12-fold (3-6-3) \\
Ba11 & $2.36(1)$ & $2.87(18)$ & 10-fold (3-6-1) \\
Ba12 & $2.30(1)$ & $2.87(16)$ & 10-fold (3-6-1) \\
Ba13 & $2.06(1)$ & $2.96(12)$ & 12-fold (3-6-3) \\
average & $2.2(2)$ & & \\
\hline Ru1 & $4.48(2)$ & $1.95(10)$ & octahedral (3-0-3) \\
Ru2 & $4.19(2)$ & $1.98(9)$ & octahedral (3-0-3) \\
Ru3 & $4.21(2)$ & $1.97(10)$ & octahedral (3-0-3) \\
Ru4 & $4.21(2)$ & $1.97(9)$ & octahedral (3-0-3) \\
Ru5 & $3.96(2)$ & $1.99(1)$ & octahedral (3-0-3) \\
Ru6 & $4.65(4)$ & $1.87(7)$ & trigonal bipyr. (1-3-1) \\
Ru7 & $4.63(4)$ & $1.87(8)$ & trigonal bipyr. (1-3-1) \\
average & $4.3(3)$ & & \\
\hline
\end{tabular}


The nominal Ru oxidation state should be slightly higher than $5+$ according to the composition of $\mathrm{Ba}_{26} \mathrm{Ru}_{12} \mathrm{O}_{57}$. Note, that the absolute values of the bond valence sums (listed in Table 5) are not necessarily equal (or even close) to the real oxidation states, especially also because of the huge complexity of the crystal structure of $\mathrm{Ba}_{26} \mathrm{Ru}_{12} \mathrm{O}_{57}$. Note that there is a scattering in the BVS values of the $\mathrm{Ba}^{2+}$ ions (oxygen ions) of \pm 0.315 ( \pm 0.246$)$ around $2.085+(1.888-)$ which provides an indication for the reliability of the BVS in this very complex structure. A similar scattering range of \pm 0.345 of the BVS values around $4.305+$ can be observed for the Ru ions. If one would take the values serious, the bond valence sum (BVS) formalism would indicate that the oxidation state of the Ru ions with trigonal bipyramidal oxygen coordination is higher than that of the other all octahedrally oxygen coordinated $\mathrm{Ru}$ ions. Such a higher oxidation state of the Ru ions with trigonal bipyramidal oxygen coordination would be in agreement with the total oxygen composition. Note, that a trigonal bipyramidal oxygen coordination is known to exist for $\mathrm{Ru}$ ions e.g., in $\mathrm{K}_{2} \mathrm{Ru}(\mathrm{OH})_{2} \mathrm{O}_{3}$ [25]. Nevertheless, the scattering of all the BVS values is somewhat enhanced (see above) and future $\mathrm{X}$-ray absorption spectroscopy measurements are required to study the real $\mathrm{Ru}$ valencies in $\mathrm{Ba}_{26} \mathrm{Ru}_{12} \mathrm{O}_{57}$.

Besides floating zone grown single crystals also conventional solid state reaction under ambient pressure conditions (air) was successful. We conclude that $\mathrm{Ba}_{26} \mathrm{Ru}_{12} \mathrm{O}_{57}$ is the ambient pressure phase within the phase diagram. Note, that high pressures of several GPa are needed to stabilize $\mathrm{Ba}$ ruthenates with layered perovskite $\left(\mathrm{K}_{2} \mathrm{NiF}_{4}\right)$ structure for Ba to Ru ratios of 2:1 [17]. For smaller Ba:Ru ratios (like 2:1.1), we observed the formation of a $\mathrm{Ba}_{4} \mathrm{Ru}_{3} \mathrm{O}_{10}$ impurity phase that is growing under the same growth conditions during our floating zone growth.

\section{Conclusions}

In summary, we synthesized the new $\mathrm{Ba}$ ruthenate compound $\mathrm{Ba}_{26} \mathrm{Ru}_{12} \mathrm{O}_{57}$. Within the ternary system $\mathrm{Ba}-\mathrm{Ru}-\mathrm{O}$ this compound is stable at ambient pressure for $\mathrm{Ba}$ to $\mathrm{Ru}$ ratios close to 2:1. Its pseudo-hexagonal crystal structure has been determined by means of single crystal X-ray diffraction and consists of alternating double and single layers of $\mathrm{Ru}$. In the double layers the $\mathrm{Ru}$ ions are dimerized $\left(\mathrm{Ru}_{2} \mathrm{O}_{9}\right)$ whereas the $\mathrm{Ru}$ ions in the single layers with trigonal bipyramidal coordination $\left(\mathrm{RuO}_{5}\right)$ are forming a distorted Kagome lattice which is "decorated" by octahedrally oxygen coordinated $\mathrm{Ru}$ ions $\left(\mathrm{RuO}_{6}\right)$ in the central free space within the Kagome lattice.

Supplementary Materials: The following are available online at http:/ / www.mdpi.com/2073-4352/10/5/355/s1, Crystal structure of Cif file.

Author Contributions: project management: A.C.K., chemical synthesis: J.-E.L., A.C.K., EDX measurements: U.B., X-ray measurements: A.C.K., J.-E.L., manuscript writing: all authors contributed. All authors have read and agreed to the published version of the manuscript.

Funding: The research in Dresden is (partially) supported by the Deutsche Forschungsgemeinschaft through Grant No. 320571839.

Acknowledgments: We thank D. I. Khomskii for helpful discussions. We acknowledge support from the Max Planck-POSTECH-Hsinchu Center for Complex Phase Materials.

Conflicts of Interest: The authors declare no conflict of interest.

\section{References}

1. Longo, J.M.; Raccah, P.M.; Goodenough, J.B. Magnetic Properties of $\mathrm{SrRuO}_{3}$ and $\mathrm{CaRuO}_{3}$. J. Appl. Phys. 1968, 39, 1327. [CrossRef]

2. Grigera, S.A.; Perry, R.S.; Schofield, A.J.; Chiao, M.; Julian, S.R.; Lonzarich, G.G.; Ikeda, S.I.; Maeno, Y.; Millis, A.J.; Mackenzie, A.P. Magnetic field-tuned quantum criticality in the metallic ruthenate $\operatorname{Sr}_{3} \mathrm{Ru}_{2} \mathrm{O}_{7}$. Science 2001, 294, 329. [CrossRef] [PubMed]

3. Perry, R.S.; Galvin, L.M.; Grigera, S.A.; Capogna, L.; Schofield, A.J.; Mackenzie, A.P.; Chiao, M.; Julian, S.R.; Ikeda, S.I.; Nakatsuji, S.; et al. Metamagnetism and critical fluctuations in high quality single crystals of the bilayer ruthenate $\mathrm{Sr}_{3} \mathrm{Ru}_{2} \mathrm{O}_{7}$. Phys. Rev. Lett. 2001, 86, 2661. [CrossRef] [PubMed] 
4. Maeno, Y.; Hashimoto, H.; Yoshida, K.; Nishizaki, S.; Fujita, T.; Bednorz, J.G.; Lichtenberg, F. Superconductivity in a layered perovskite without copper. Nature 1994, 372, 532. [CrossRef]

5. Koster, G.; Klein, L.; Siemons, W.; Rijnders, G.; Dodge, J.S.; Eom, C.-B.; Blank, D.H.A.; Beasley, M.R. Structure, physical properties, and applications of $\mathrm{SrRuO}_{3}$ thin films. Rev. Mod. Phys. 2012, 84, 253. [CrossRef]

6. Eremin, I.; Manske, D.; Ovchinnikov, S.G.; Annett, J.F. Unconventional superconductivity and magnetism in $\mathrm{Sr}_{2} \mathrm{RuO}_{4}$ and related materials. Ann. Phys. 2004, 13, 149-174. [CrossRef]

7. Li, Z.; Liu, C.-F.; Skoulatos, M.; Tjeng, L.; Komarek, A. Floating zone growth of Ba-substituted ruthenate $\mathrm{Sr}_{2-x} \mathrm{BaxRuO}_{4}$. J. Cryst. Growth 2015, 427, 94. [CrossRef]

8. Li, Z.W.; Guo, H.; Liu, C.-F.; Bourdarot, F.; Schmidt, W.; Skoulatos, M.; Komarek, A.C. Spin fluctuations in $\mathrm{Sr}_{1.6} \mathrm{Ba}_{0.4} \mathrm{RuO}_{4}$ : An inelastic neutron scattering study with polarization analysis. Phys. Rev. B 2017, 95, 045105. [CrossRef]

9. Chandrasekaran, K.; Vijayaraghavan, R.; Varadaraju, U.V. Effects of oxygen non-stoichiometry and cationic substitutions on the properties of $\mathrm{Sr}_{2} \mathrm{RuO}_{4+x}$. Materials chemistry and physics. Mater. Chem. Phys. 1998, 56, 63-69. [CrossRef]

10. Hong, S.-T.; Sleight, A.W.J. Scanning transmission electron microscopy (STEM) and X-ray absorption spectroscopy (XAS) investigations of catalytic systems. Solid State Chem. 1997, 128, 251-255. [CrossRef]

11. Donohue, P.C.; Katz, L.; Ward, R. The crystal structure of barium ruthenium oxide and related compounds. Inorg. Chem. 1965, 4, 306-310. [CrossRef]

12. Igarashi, T.; Nogami, Y.; Klein, Y.; Rousse, G.; Okazaki, R.; Taniguchi, H.; Yasui, Y.; Terasaki, I. X-ray Crystal Structure Analysis and $\mathrm{Ru}$ Valence of $\mathrm{Ba}_{4} \mathrm{Ru}_{3} \mathrm{O}_{10}$ Single Crystals. J. Phys. Soc. Jpn. 2013, 82, 104603. [CrossRef]

13. Klein, Y.; Rousse, G.; Damay, F.; Porcher, F.; André, G.; Terasaki, I. Antiferromagnetic order and consequences on the transport properties of $\mathrm{Ba}_{4} \mathrm{Ru}_{3} \mathrm{O}_{10}$. Phys. Rev. B 2011, 84, 054439. [CrossRef]

14. Dussarra, C.; Grasse, F.; Bontchev, R.; Darriet, J. Crystal structures and magnetic properties of $\mathrm{Ba}_{4} \mathrm{Ru}_{3} \mathrm{O}_{10}$ and $\mathrm{Ba}_{5} \mathrm{Ru}_{3} \mathrm{O}_{12}$. J. Alloys Compd. 1996, 233, 15-22. [CrossRef]

15. Grasset, F.; Zakhour, M.; Darriet, J. Synthesis, crystal structure and magnetic properties of $\mathrm{Ba}_{5} \mathrm{Ru}_{2} \mathrm{O}_{9}\left(\mathrm{O}_{2}\right)$, $\mathrm{Ba}_{5} \mathrm{Nb}_{2} \mathrm{O}_{9}\left(\mathrm{O}_{2}\right)$ and $\mathrm{Ba}_{5} \mathrm{Ru}_{2} \mathrm{O}_{10}$ related to the perovskite-type structure, and structural relationships with corresponding sulfides. J. Alloys Compd. 1999, 287, 25-31. [CrossRef]

16. Jia, Y.; Zurbuchen, M.A.; Wozniak, S.; Carim, A.H.; Schlom, D.G. Epitaxial growth of metastable $\mathrm{Ba}_{2} \mathrm{RuO}_{4}$ films with the $\mathrm{K}_{2} \mathrm{NiF}_{4}$ structure. Appl. Phys. Lett. 1999, 74, 3830. [CrossRef]

17. Kafalas, J.A.; Longo, J.M. High pressure synthesis of $\left(\mathrm{ABX}_{3}\right)(\mathrm{AX}) \mathrm{n}$ compounds. J. Solid State Chem. 1972, 4, 55. [CrossRef]

18. Rodrguez-Carvajal, J. Recent advances in magnetic structure determination by neutron powder diffraction. Physics B 1993, 192, 55-69. [CrossRef]

19. Petricek, V.; Dusek, M.; Palatinus, L. Crystallographic computing system JANA2006: General features. Z. Kristallogr. 2014, 229, 345.

20. Takeda, Y.; Kanamura, F.; Shimada, M.; Koizumi, M. The crystal structure of $\mathrm{BaNiO}_{3}$. Acta Cryst. B 1976, 32, 2464-2466. [CrossRef]

21. Tillmanns, E.; Grosse, H.-P. Refinement of tribarium silicate. Acta Cryst. B 1978, 34, 649-651. [CrossRef]

22. Bekker, T.B.; Rashchenko, S.V.; Seryotkin, Y.V.; Kokh, A.E.; Davydov, A.V.; Fedorov, P.P. BaO-B $\mathrm{O}_{3}$ system and its mysterious member $\mathrm{Ba}_{3} \mathrm{~B}_{2} \mathrm{O}_{6}$. J. Am. Ceram. Soc. 2018, 101, 450-457. [CrossRef]

23. Kipka, R.; Mueller-Buschbaum, H. Uber Oxocuprate. XIX. Ein Oxohalogenocuprat (I): $\mathrm{Ba}_{2} \mathrm{CuO}_{2} \mathrm{Cl}$. Anorg. Allg. Chem. 1977, 430, 250-254. [CrossRef]

24. Brese, N.E.; O’Keeffe, M. Bond-valence parameters for solids. Acta Cryst. B 1991, 47, 192-197. [CrossRef]

25. Fischer, D.; Hoppe, R.Z. Zur Konstitution von Alkaliruthenaten (VI).2. Uber den Aufbau von $\mathrm{K}_{2}\left[\mathrm{RuO}{ }_{3}(\mathrm{OH})_{2}\right]$. Anorg. Allg. Chem. 1991, 601, 41-46. [CrossRef]

(C) 2020 by the authors. Licensee MDPI, Basel, Switzerland. This article is an open access article distributed under the terms and conditions of the Creative Commons Attribution (CC BY) license (http://creativecommons.org/licenses/by/4.0/). 